\title{
Nuclear translocation of cysteinyl leukotriene receptor 1 is involved in oxygen-glucose deprivation- induced damage to endothelial cells
}

\author{
San-hua FANG ${ }^{1, \#}$, Ka-na $\mathrm{LIN}^{1,2, \#}$, Xue-qin $\mathrm{HUANG}^{1}$, Yun-bi LU ${ }^{1}$, Wei-ping ZHANG ${ }^{1}$, Er-qing WEI ${ }^{1, \text { * }}$ \\ ${ }^{1}$ Institute of Neuroscience and Department of Pharmacology, School of Medicine, Zhejiang University, Hangzhou 310058, China; \\ ${ }^{2}$ Department of Pharmacology, Second Affiliated Hospital (Binjiang Branch), Zhejiang University, Hangzhou 310009, China
}

Aim: Cysteinyl leukotriene receptor 1 (CysLT 1 receptor) is located in epithelial cells, and translocates from the plasma membrane to the nucleus in a ligand-dependent manner. Here, we investigated whether $\mathrm{Cys}_{1} \mathrm{~T}_{1}$ receptors translocated to the nucleus in endothelial cells after ischemic insult in vitro and whether it was involved in ischemic injury to endothelial cells.

Methods: EA.hy926 cell line, derived from human umbilical vein endothelial cells, was subjected to oxygen-glucose deprivation (OGD). The expression and distribution of $\mathrm{CysLT}_{1}$ receptors were detected by immunofluorescent staining, immunogold labeling and immunoblotting analyses. Cell viability was evaluated using MTT reduction assay. Necrosis and apoptosis were determined by double fluorescent staining with propidium iodide and Hoechst 33342.

Results: CysLT 1 receptors were primarily distributed in the cytoplasm and nucleus in EA.hy926 cells, and few was found in the cell membrane. OGD induced the translocation of $\mathrm{CysLT}_{1}$ receptors from the cytoplasm to the nucleus in a time-depen dent manner, with a peak

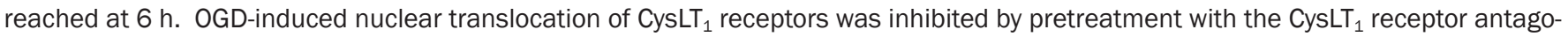
nist pranlukast $(10 \mu \mathrm{mol} / \mathrm{L})$, or by preincubation with NLS-pep, a peptide corresponding to the nuclear localization sequence of CysLT 1 receptor $(10 \mu \mathrm{g} / \mathrm{mL})$. However, zileuton, an inhibitor of 5-lipoxygenase that was a key enzyme in cysteinyl leukotriene generation, did

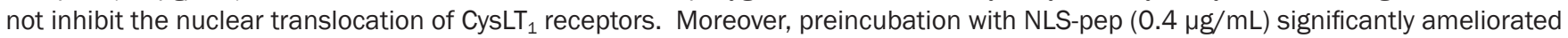
OGD-induced cell viability reduction and necrosis.

Conclusion: CysLT 1 receptors in endothelial cells translocate to the nucleus in a ligand-independent manner after ischemic insult in vitro, and it is involved in the ischemic injury.

Keywords: cysteinyl leukotriene receptor 1; nuclear translocation; endothelial cell; ischemic insult; oxygen-glucose deprivation; necrosis; apoptosis; pranlukast; zileuton

Acta Pharmacologica Sinica (2012) 33: 1511-1517; doi: 10.1038/aps.2012.101; published online 22 Oct 2012

\section{Introduction}

Cysteinyl leukotrienes (CysLTs), namely $\mathrm{LTC}_{4}, \mathrm{LTD}_{4}$, and $\mathrm{LTE}_{4}$, are important inflammatory mediators produced from arachidonic acid via the 5-lipoxygenase (5-LOX) pathway. CysLTs exert their actions through the activation of the CysLT and $\mathrm{CysLT}_{2}$ receptors, which are G-protein-coupled receptors (GPCRs) ${ }^{[1]}$. The CysLT $_{1}$ receptor has been extensively studied, and its selective antagonists have been used for the treatment of bronchial asthma ${ }^{[2]}$. Generally, CysLT $\mathrm{C}_{1}$ receptor ligands initiate a series of intracellular signaling events by interacting with the receptor on the plasma membrane ${ }^{[2]}$. However,

\footnotetext{
\# These authors contributed equally to this work.

* To whom correspondence should be addressed.

E-mail weieq2006@zju.edu.cn

Received 2012-01-08 Accepted 2012-07-02
}

the $\mathrm{CysLT}_{1}$ receptor is also localized in the nuclear envelope in colon cancer cells and the epithelial cell line Int 407. The ligand $\mathrm{LTD}_{4}$ also induces translocation of the CysLT 1 receptor from the plasma membrane to the nucleus ${ }^{[3,4]}$. In the process of nuclear translocation, a nuclear localization sequence (NLS) is necessary for the nuclear import of proteins. An NLS is contained within the structure of the $\mathrm{CysLT}_{1}$ receptor. Mutation of the NLS inhibits nuclear translocation of the CysLT receptor and $\mathrm{LTD}_{4}$-induced cell proliferation ${ }^{[3]}$. The nuclear distribution and translocation of the $\mathrm{CysLT}_{1}$ receptor may regulate physiological processes in cells. Previous studies have suggested that the nuclear distribution of the CysLT $_{1}$ receptor may be involved in tumor cell proliferation ${ }^{[3,4]}$. However, whether pathological stimuli can induce the nuclear translocation of the $\mathrm{CysLT}_{1}$ receptor remains unknown.

The CysLT 1 receptor mediates various pathophysiological 
responses in different disease processes. One typical response is a $\mathrm{CysLT}_{1}$ receptor-mediated change in vascular permeability. We have reported that the $\mathrm{CysLT}_{1}$ receptor mediates ischemic brain injury in vivo ${ }^{[5,6]}$. This effect is potentially governed by a $\mathrm{CysLT}_{1}$ receptor-mediated increase in blood-brain barrier permeability and, consequently, brain edema, after ischemia ${ }^{[7,8]}$. Endothelial cells are crucial to vascular permeability; thus, their injury or death after ischemia may contribute to secondary post-ischemic injury and tissue edema ${ }^{[9,10]}$. We have reported that the $\mathrm{CysLT}_{1}$ receptor antagonist pranlukast protects endothelial cells against ischemia-like injury ${ }^{[11]}$. However, the distribution of the $\mathrm{CysLT}_{1}$ receptor in endothelial cells after ischemia is not known. In intestinal epithelial cells, the $\mathrm{CysLT}_{1}$ receptor translocates to the nucleus after stimulation by the ligand $\mathrm{LTD}_{4}$, which mediates cell proliferation ${ }^{[3]}$. Based on these findings, whether ischemia induces nuclear translocation of the $\mathrm{CysLT}_{1}$ receptor and how this translocation affects ischemic injury warrants further study.

Therefore, we investigated whether the $\mathrm{CysLT}_{1}$ receptor translocates to the nucleus after in vitro ischemia and its involvement in ischemic injury to endothelial cells. In this study, the EA.hy926 cell line, derived from human umbilical vein endothelial cells (HUVECs), was used. This cell line displays a wide range of properties ascribed to differentiated endothelial cells and has been used to investigate endothelial cell inflammatory responses ${ }^{[12-14]}$.

\section{Materials and methods}

\section{Cell culture and oxygen-glucose deprivation (OGD)}

EA.hy926 cells were a kind gift from Dr CJ EDGELL (University of North Carolina, Chapel Hill, NC, USA). Cells were cultured in Dulbecco's modified Eagle's medium (DMEM, Gibco, Grand Island, NY, USA), supplemented with 10\% heatinactivated fetal calf serum, penicillin $(100 \mathrm{U} / \mathrm{mL})$ and streptomycin $(100 \mathrm{mg} / \mathrm{mL})$. Experiments were conducted $24 \mathrm{~h}$ after cells were seeded.

OGD was performed as described previously ${ }^{[15]}$. Briefly, the original medium was removed; the cells were washed twice with glucose-free Earle's balanced salt solution (EBSS) and placed in fresh glucose-free EBSS. Cultures were then placed in an incubator containing $5 \% \mathrm{CO}_{2}$ and $95 \% \mathrm{~N}_{2}$ at $37^{\circ} \mathrm{C}$ for 2 to $8 \mathrm{~h}$. Control cultures were maintained in glucose-containing EBSS under normal conditions. Ten $\mu \mathrm{mol} / \mathrm{L}$ pranlukast (a gift from Ono Pharmaceutical Co, Osaka, Japan), $10 \mu \mathrm{mol} / \mathrm{L}$ zileuton, a 5-LOX inhibitor (Comens Chemical Co, Beijing, China) or $10 \mu \mathrm{mol} / \mathrm{L}$ pyrrolidine dithiocarbamate (PDTC), a specific NF-kB inhibitor (Aldrich-Sigma, Saint Louis, MO, USA), was added to the culture $30 \mathrm{~min}$ before OGD exposure and maintained during OGD.

\section{Osmotic loading of synthetic peptides into EA.hy926 cells}

A peptide corresponding to a putative NLS of the CysLT receptor [amino acids 312-323, (NLS-pep)], and its mutant, in which the NLS was replaced by a non-NLS of CysLT [amino $^{2}$ acids 323-330, (NLS-mut)], were synthesized by GL Biochem Ltd (Shanghai, China) ${ }^{[3]}$. Osmotic loading of peptides was per- formed as described previously ${ }^{[16,17]}$. In brief, EA.hy926 cells were rinsed in glucose-containing EBSS, incubated for $10 \mathrm{~min}$ with loading solution $(0.5 \mathrm{~mol} / \mathrm{L}$ sucrose, $10 \%$ polyethylene glycol 1000, 10\% FBS, and 10 mg/mL NLS-pep or NLS-mut in DMEM, buffered with $25 \mathrm{mmol} / \mathrm{L}$ HEPES, pH 6.8), and then rapidly rinsed with a hypotonic solution (6.5 vol $\mathrm{H}_{2} \mathrm{O}: 3.5 \mathrm{vol}$ DMEM, buffered with $25 \mathrm{mmol} / \mathrm{L}$ HEPES, pH 6.8). Cells were then incubated in DMEM and used immediately for experiments.

\section{Nuclear isolation and immunoblotting}

EA.hy926 cells were rinsed twice with ice-cold PBS and collected with a cell scraper. The cell membrane, cytosolic and nuclear fractions were extracted using a protein extraction kit (DBI-1031, DBI, USA) according to the manufacturer's instructions. The protein concentration was determined by Coomassie blue protein assay. To determine CysLT $\mathrm{T}_{1}$ receptor expression, samples (30 $\mathrm{\mu g}$ protein) were separated by $10 \%$ SDS-polyacrylamide gel electrophoresis and then electrically transferred to nitrocellulose membranes. The membranes were blocked with $5 \%$ bovine serum albumin and incubated overnight at $4{ }^{\circ} \mathrm{C}$ with a rabbit polyclonal antibody against the CysLT $_{1}$ receptor (1:100, Cayman Chemical, USA). Then, the membranes were washed repeatedly and incubated with IRDye $^{\mathrm{TM}} 700$ conjugated affinity-purified anti-rabbit IgG (1:8000, Rockland Immunochemicals, Inc, USA). Finally, the protein bands were detected using an Odyssey fluorescent scanner (LI-COR Bioscience, USA). The purity of subcellular fractions was routinely verified by immunoblotting with antibodies specific for markers of different subcellular components: CD44 for the plasma membrane, GAPDH for the cytoplasm, and lamin B for the nucleus. Data are reported as fold increases compared with control cells.

\section{Immunofluorescent staining}

EA.hy926 cells cultured on coverslips were fixed with cold methanol $\left(-20^{\circ} \mathrm{C}\right)$ for $5 \mathrm{~min}$ and subsequently incubated with $10 \%$ normal goat serum for $120 \mathrm{~min}$. Cells were then incubated with a rabbit polyclonal antibody against the $\mathrm{CysLT}_{1}$ receptor (1:100, Cayman Chemical, USA) or a rabbit polyclonal antibody against NF-kB (1:50, Santa Cruz Biotechnology, Santa Cruz, CA, USA) as the primary antibody at $4^{\circ} \mathrm{C}$ overnight. After washing with PBS, the cells were incubated for $2 \mathrm{~h}$ with FITC-conjugated goat anti-rabbit IgG antiserum (1:200, Chemicon, USA) and examined under a fluorescence microscope (Olympus X51) or a laser scanning confocal microscope (Olympus FV1000). Control coverslips were incubated with normal goat serum instead of the primary antibody, and no positive staining was observed.

\section{Cell viability and cell death}

Cell viability was evaluated by the MTT reduction assay. At the end of OGD, the media were removed, and the cells were incubated in $0.5 \mathrm{mg} / \mathrm{mL}$ 3-(4,5-dimethyl-2-thiazolyl)-2,5diphenyl-2H-tetrazolium bromide (MTT) solution for $2 \mathrm{~h}$ in a humidified $5 \% \mathrm{CO}_{2}$ incubator at $37^{\circ} \mathrm{C}$. The incubation was 
stopped by removing the media and adding dimethylsulfoxide (DMSO) to solubilize the formed formazan salt. The absorbance of formazan was read at $490 \mathrm{~nm}$ on a microplate reader (ELX800, Bio-Tex Instruments Inc, USA). Data are reported as the percentage of the absorbance in control cells.

As described previously, death of endothelial cells by necrosis and apoptosis was determined by double fluorescent staining with propidium iodide (PI) and Hoechst $33342^{[11]}$. In brief, monolayers of cells on slides were stained with PI $(10 \mu \mathrm{g} / \mathrm{mL})$ and Hoechst $33342(10 \mu \mathrm{g} / \mathrm{mL})$ for $10 \mathrm{~min}$ at $37^{\circ} \mathrm{C}$. After washing with EBSS, the cells were fixed in 3.7\% $(v / v)$ paraformaldehyde and then examined under a fluorescence microscope. The necrotic cells stained red by PI and the apoptotic cells showed nuclear condensation and fragmentation after Hoechst 33342 staining. The total necrotic and apoptotic cells were counted, and the percentages of necrotic and apoptotic cells were calculated.

\section{Statistical analysis}

Data are presented as mean \pm SEM. For statistical comparisons, differences between groups were analyzed by a one-way analysis of variance (ANOVA), followed by Dennett's post-hoc test. A value of $P<0.05$ was considered to be statistically significant.

\section{Results}

The CysLT 1 receptor is localized in the nuclear compartment

The subcellular distribution of the $\mathrm{CysLT}_{1}$ receptor in EA.hy926 cells was analyzed by confocal microscopy after immunofluorescent staining and by electron microscopy after immunogold labeling. Immunofluorescent staining showed that the CysLT $_{1}$ receptor was primarily distributed in the cytoplasm and the nucleus (Figure 1A). This result was verified by immunogold labeling followed by electron microscopy (Figure 1B). To further confirm the nuclear localization of the CysLT receptor, the nuclei were isolated, and the purity of the nuclear fraction was confirmed by immunoblotting with markers for the nucleus (Lamin B), cell membrane (CD44) and cytoplasm
(GAPDH). Lamin B was detected only in the purified nuclear fraction. The CysLT $\mathrm{T}_{1}$ receptor was primarily detected in the nuclear and cytosolic fractions, and little was detected in the cell membrane (Figure 1C). The specificity of anti-CysLT 1 receptor antibody (Cayman Chemical) used in these experiments has been verified in previous reports ${ }^{[18,19]}$.

\section{OGD-induced nuclear translocation of the CysLT $_{1}$ receptor}

Next, we determined whether induction of in vitro ischemia by OGD induces nuclear translocation of the $\mathrm{CysLT}_{1}$ receptor. We found that the $\mathrm{CysLT}_{1}$ receptor in the nucleus increased gradually after OGD, and $\mathrm{CysLT}_{1}$ receptor-positive staining was almost entirely distributed in the nucleus 6 or $8 \mathrm{~h}$ after OGD (Figure 2A). The results were verified by immunoblotting assay, which showed that the amount of $\mathrm{CysLT}_{1}$ receptor in the nucleus significantly increased 4-8 h after OGD, with the maximum at $6 \mathrm{~h}$ (Figure 2D), whereas the amount of $\mathrm{CysLT}_{1}$ receptor in the cytoplasm decreased (Figure 2C). In addition, we found no change in the total $\mathrm{CysLT}_{1}$ receptor expression level after OGD (Figure 2B).

\section{NLS-pep and a CysLT 1 receptor antagonist inhibit the nuclear} translocation of the CysLT $_{1}$ receptor

Because a peptide corresponding to the NLS inhibits nuclear translocation of the corresponding protein ${ }^{[17]}$, we used the peptide corresponding to the NLS of the CysLT $_{1}$ receptor (NLSpep) to determine its effect on translocation. The results show that preincubation with NLS-pep significantly inhibited OGDinduced nuclear translocation of the $\mathrm{CysLT}_{1}$ receptor, whereas the control NLS-mut had no effect (Figure 3A and 3B). The inhibitory effect of NLS-pep was specific to the CysLT $\mathrm{T}_{1}$ receptor because NLS-pep had no effect on OGD-induced nuclear translocation of NF-kB (Figure 4). We also assessed the effects of the $\mathrm{CysLT}_{1}$ receptor antagonist pranlukast and the 5-lipoxygenase inhibitor zileuton on translocation. The results showed that pranlukast, but not zileuton, inhibited the translocation of the CysLT $_{1}$ receptor $6 \mathrm{~h}$ after OGD (Figure 3A and 3C).
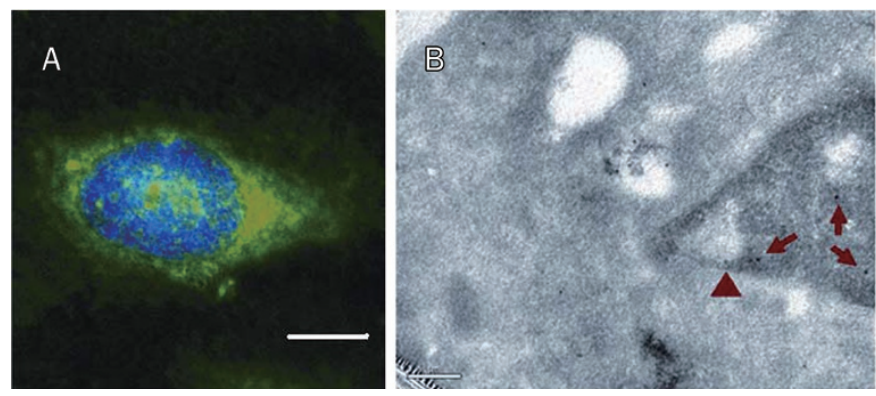

C

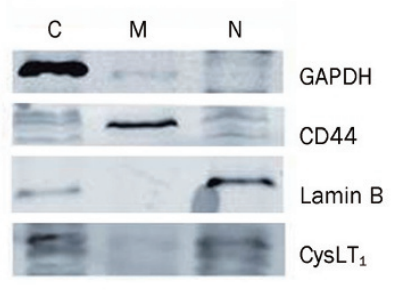

Figure 1. Nuclear localization of the $\mathrm{CysLT}_{1}$ receptor in EA.hy926 cells. Confocal microscopy assay showing $\mathrm{CysLT}_{1}$ receptor distribution after immunostaining and DAPI counterstaining (A). Immunogold detection of nuclear CysLT 1 receptors (B). EA.hy926 cells were immunostained with antibody against the $\mathrm{CysLT}_{1}$ receptor followed by gold-particle conjugated secondary antibody. Arrows indicate gold particles, and arrow heads indicate the nuclear envelope. Immunoblotting analysis of $\mathrm{Cys}_{1} \mathrm{LT}_{1}$ receptor expression (C). The membrane (M), cytosolic (C), and nuclear (N) fractions were extracted, and equal amounts of proteins were used for SDS polyacrylamide gel analysis. The purity of subcellular fractions was verified by immunoblotting for CD44 for the plasma membrane, GAPDH for the cytoplasm, and lamin B for the nucleus. Scale bar=5 $\mu \mathrm{m}$ in Figure $1 \mathrm{~A}$ and $0.5 \mu \mathrm{m}$ in Figure 1B. 
A
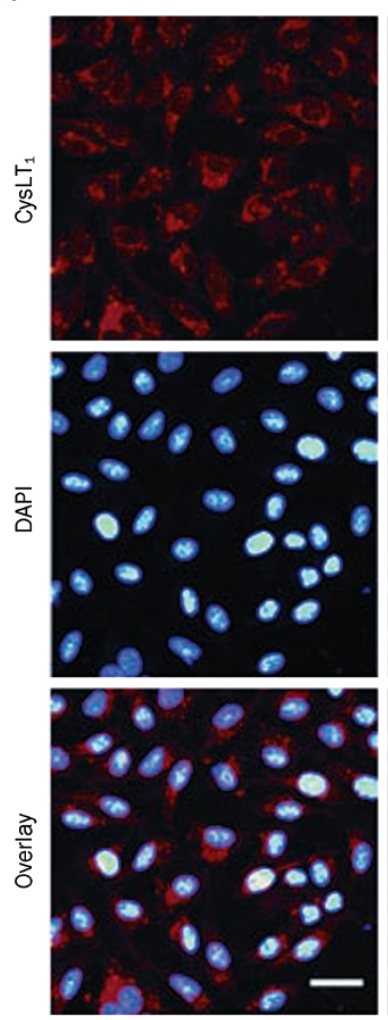

OGD $2 \mathrm{~h}$



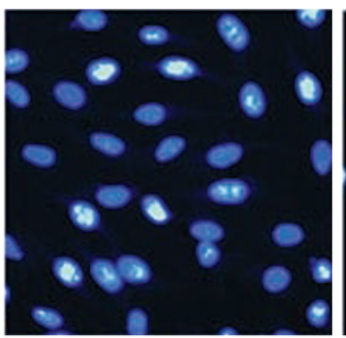

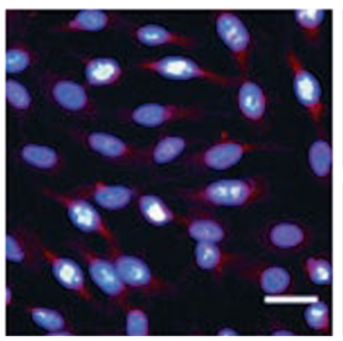

OGD $4 \mathrm{~h}$

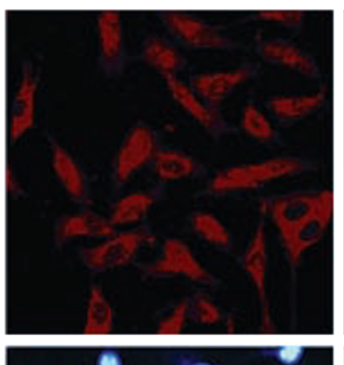


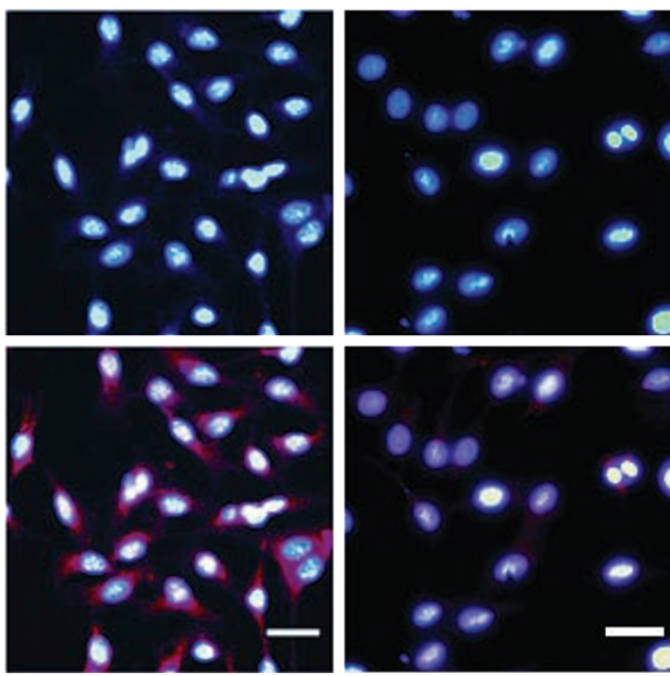

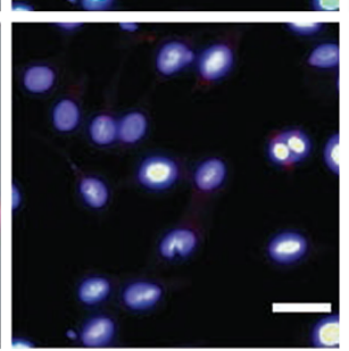

OGD $8 \mathrm{~h}$

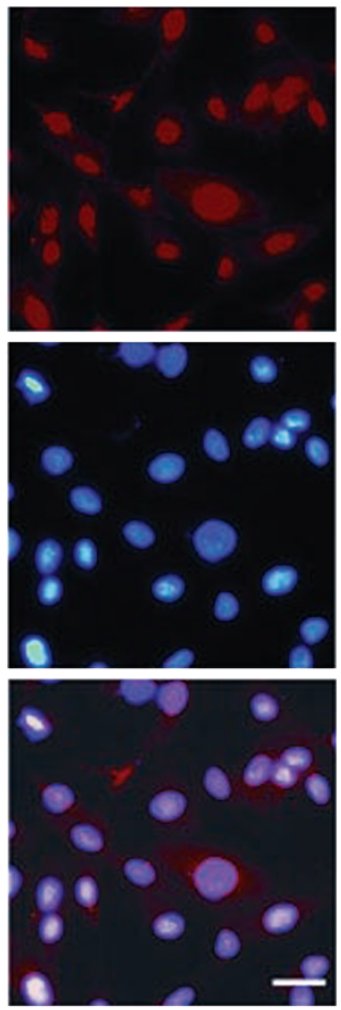

B


C


D


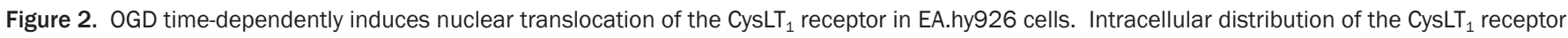
(A), immunoblotting analysis of CysLT $\mathrm{T}_{1}$ receptor expression (B), immunoblotting analysis of the $\mathrm{CysLT}_{1}$ receptor in the cytoplasmic fraction (C), and immunoblotting analysis of the CysLT $T_{1}$ receptor in the nuclear fraction (D) after OGD are shown. OGD did not change the CysLT 1 receptor expression level, but induced nuclear translocation of the $\mathrm{CysLT}_{1}$ receptor in a time-dependent manner. Data are expressed as mean $\pm \mathrm{SEM}, n=4$ experiments and ${ }^{\mathrm{b}} P<0.05$ vs control. Data were analyzed by one-way ANOVA. Ctrl, control; OGD, oxygen-glucose deprivation. Scale bar $=50 \mu \mathrm{m}$.

Nuclear translocation of the CysLT $_{1}$ receptor is involved in OGDinduced cell damage

Finally, we investigated whether nuclear translocation of the CysLT $_{1}$ receptor is involved in OGD-induced cell damage. OGD reduced cell viability in a time-dependent manner (data not shown). Cell viability was reduced by $34 \%$ at $6 \mathrm{~h}$ after OGD as determined by the MTT reduction assay. The addition of NLS-pep or NLS-mut alone did not induce any cell damage (Figure 5A). The presence of NLS-pep significantly increased cell viability after OGD, whereas NLS-mut did not 
A

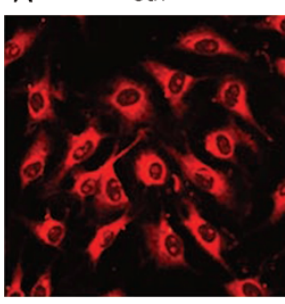

OGD

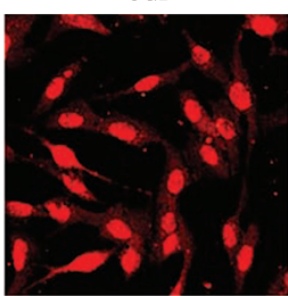

OGD+NLS-mut



OGD+NLS-pep

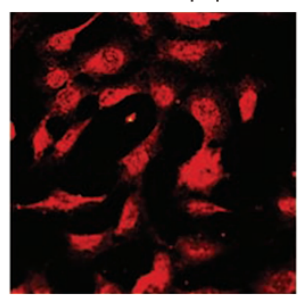

OGD+Pran

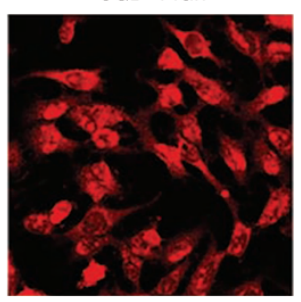

OGD+Zileu

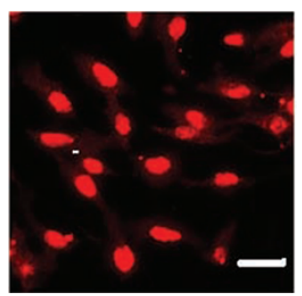

B


C
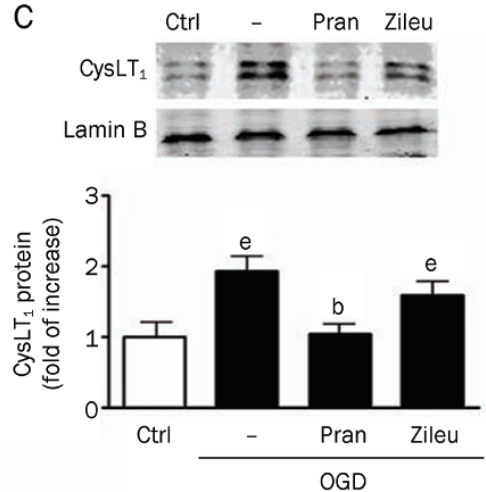

Figure 3. NLS-pep and pranlukast inhibit OGD-induced nuclear translocation of the CysLT $_{1}$ receptor in EA.hy926 cells. Six hours of OGD significantly induced nuclear translocation of the CysLT $T_{1}$ receptor. The translocation was reduced by NLS-pep (a peptide corresponding to the NLS of the CysLT 1 receptor) and pranlukast (a CysLT 1 receptor antagonist), but not by NLS-mut or zileuton (a 5 -lipoxygenase inhibitor). Data are expressed as mean $\pm S E M$, $n=4,{ }^{b} P<0.05$ vs control, ${ }^{e} P<0.05$. Data were analyzed by one-way ANOVA. Ctrl, control; OGD, oxygen-glucose deprivation; Pran, pranlukast; Zileu, zileuton. Scale bar $=50 \mu \mathrm{m}$.

Ctrl

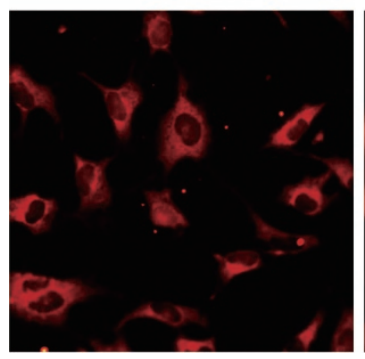

OGD

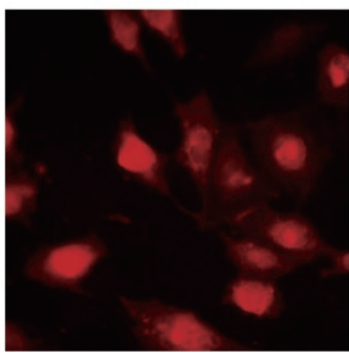

OGD+PDTC

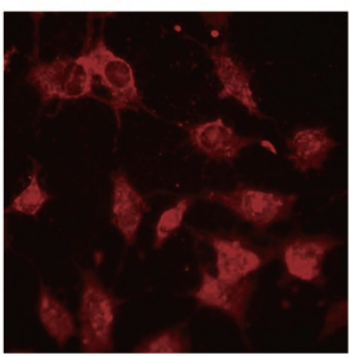

OGD+NLS-pep



OGD+NLS-mut

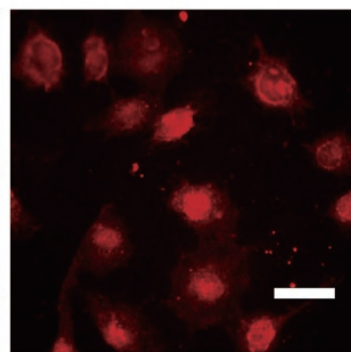

Figure 4. NLS-pep does not inhibit OGD-induced nuclear translocation of NF-KB in EA.hy926 cells. Eight hours of OGD significantly induced nuclear translocation of NF-kB. The translocation was reduced by PDTC (a specific NF-KB inhibitor), but not by NLS-pep or NLS-mut. Ctrl, control; OGD, oxygenglucose deprivation; PDTC, pyrrolidine dithiocarbamate. Scale bar $=50 \mu \mathrm{m}$.

have this effect (Figure 5A).

Many necrotic cells and a few apoptotic cells were detected $6 \mathrm{~h}$ after OGD (Figure 5B). Necrosis was the main pathway of OGD-induced cell death, which is consistent with the findings of our previous study ${ }^{[11]}$. OGD-induced necrosis was significantly reduced by $0.4 \mu \mathrm{g} / \mathrm{mL}$ NLS-pep (from 35\% to $23 \%$ ), but not by NLS-mut (Figure 5B and 5C). In addition, we found that pranlukast, but not zileuton, protected EA.hy926 cells against OGD-induced damage (data not shown), similar to our previous study ${ }^{[11]}$.

\section{Discussion}

In the present study, we found that the CysLT 1 receptor in
EA.hy926 cells was primarily distributed in the cytoplasm and the nucleus, with little detected in the plasma membrane. This finding differs from that in epithelial cells and mast cells, in which the CysLT $_{1}$ receptor is primarily distributed in the plasma membrane and the nucleus ${ }^{[3,19]}$. This difference may be cell-type specific, because the same anti-CysLT $\mathrm{T}_{1}$ receptor antibody was used here and in other studies ${ }^{[3,19]}$.

The most important finding is that the $\mathrm{CysLT}_{1}$ receptor translocates from the cytoplasm to the nucleus after in vitro OGD and is involved in ischemic injury to endothelial cells. Increasing evidence has demonstrated that a number of $G$ protein-coupled receptors are located in the nuclear membrane or intranuclear sites. These receptors include members of all 
A

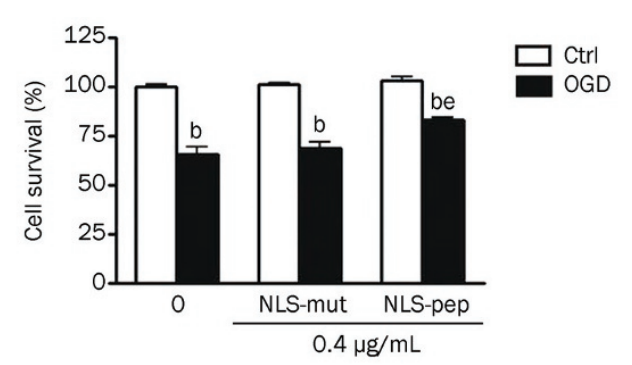

B
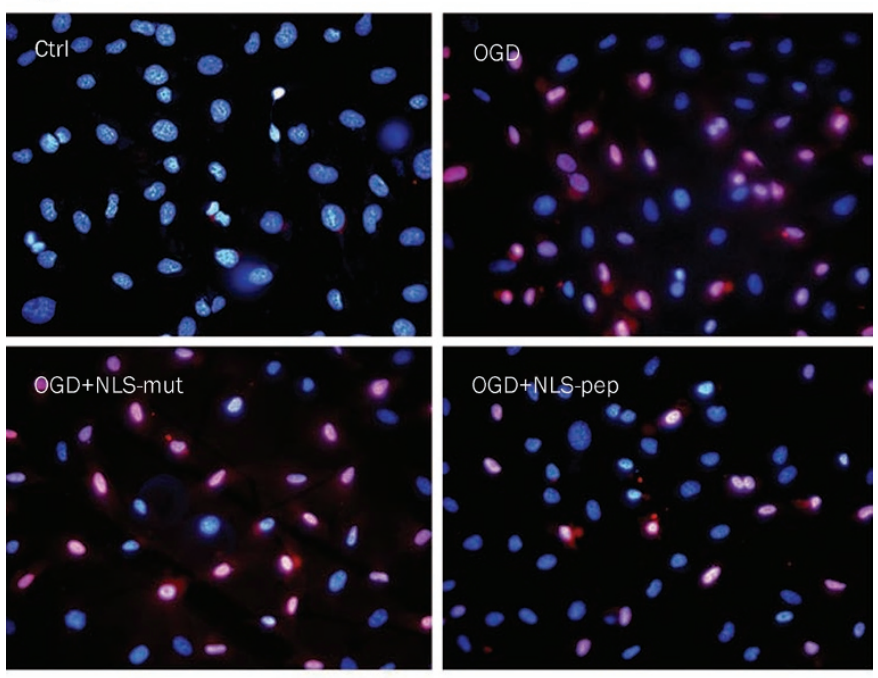

C

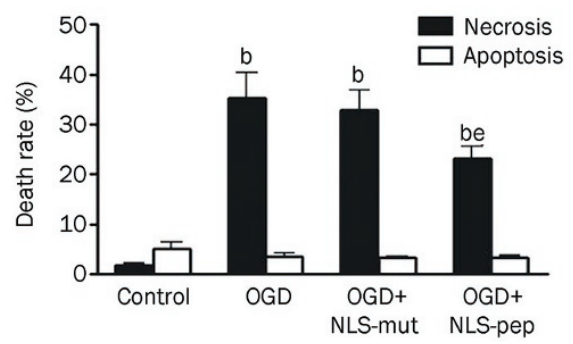

Figure 5. NLS-pep protects EA.hy926 cells from OGD-induced damage. Cell viability was determined by MTT reduction assay (A), and cell death by PI (red) and Hoechst 33342 (blue) staining (B and C). Necrosis was the primary cause of OGD-induced cell death. OGD-induced cell viability reduction and cell necrosis were ameliorated by NLS-pep, but not by NLSmut. Data are expressed as mean \pm SEM, $n=8,{ }^{b} P<0.05$ vs control, and ${ }^{\mathrm{e}} P<0.05$ vs OGD at $8 \mathrm{~h}$. Data were analyzed by one-way ANOVA. Scale bar $=50 \mu \mathrm{m}$.

major classes of GPCRs, such as lysophosphatidic acid receptor-1 (LPA1R) ${ }^{[20]}$, metabotropic glutamate receptors (mGluR5) ${ }^{[21]}$, apelin receptors ${ }^{[22]}$, platelet-activating factor (PAF) receptors ${ }^{[23]}$, angiotensin 2 type I receptors ${ }^{[17,24]}$, prostaglandin $\mathrm{EP}_{3}$ receptors ${ }^{[25]}$, endothelin receptors ${ }^{[26]}$ and $\beta$-adrenergic receptors $^{[27,28]}$. The significance of the nuclear translocation of GPCRs is not known. Limited reports have shown that nuclear LPA1R or PAF receptors modulate pro-inflammatory gene expression in cells that stably express these receptors ${ }^{[20,23]}$. Furthermore, mGluR5 on nuclear membranes mediates intra- nuclear $\mathrm{Ca}^{2+}$ changes in neurons ${ }^{[2]]}$, and nuclear $\beta$-adrenergic receptors modulate gene expression in adult rat hearts ${ }^{[28]}$. Here, we found that ischemic stimulation induced nuclear translocation of the CysLT $\mathrm{T}_{1}$ receptor in a time-dependent manner. The $\mathrm{CysLT}_{1}$ receptor was almost entirely distributed in the nucleus after 6 or $8 \mathrm{~h}$ of OGD. This nuclear distribution could be attenuated by inhibiting its nuclear import sequence using NLS-pep. Moreover, NLS-pep decreased ischemiainduced cell damage. These findings indicate that nuclear translocation of the CysLT 1 receptor is involved in ischemic injury of endothelial cells. This phenomenon is different from the ligand-induced proliferation mediated by nuclear translocation of the $\mathrm{CysLT}_{1}$ receptor in intestinal epithelial cells ${ }^{[3]}$.

The mechanisms underlying OGD-induced nuclear translocation of the $\mathrm{CysLT}_{1}$ receptor remain unknown. However, it has been reported that GPCRs are translocated from the plasma membrane to the nucleus in either a ligand-dependent ${ }^{[3,29]}$ or ligand-independent manner ${ }^{[22]}$. We found that the $\mathrm{CysLT}_{1}$ receptor antagonist pranlukast inhibited OGD-induced nuclear translocation of the receptor, but the 5-lipoxygenase inhibitor zileuton had no effect. If endogenous agonists of CysLTs induced this translocation, zileuton would be effective because it inhibits enhanced production of CysLTs after exposure to $\mathrm{OGD}^{[30]}$. Moreover, we have reported that pranlukast ligand-independently attenuates ischemic injury in EA.hy926 cells by inhibiting reactive oxygen species production and nuclear factor-kappaB activation ${ }^{[11]}$. Therefore, we suggest that the $\mathrm{CysLT}_{1}$ receptor may translocate to the nucleus after OGD, in part by a ligand-independent mechanism. Based on previous and present finding ${ }^{[3,4]}$, we hypothesize that the $\mathrm{CysLT}_{1}$ receptor exhibits ligand-dependent or ligand-independent nuclear translocation.

In conclusion, our results show that after in vitro ischemia, the $\mathrm{CysLT}_{1}$ receptor translocates to the nucleus in a ligandindependent manner and that this translocation is involved in ischemic injury to endothelial cells.

\section{Acknowledgements}

This study was supported by grants from the National Natural Science of China (81273491, 30801397, 30873053, and 81072618), Zhejiang Provincial Natural Science of China (Y207343 and Y2090069), and Fundamental Research Funds for the Central Universities (2009QNA7008). We thank Dr IC BRUCE for critically reading and revising this manuscript.

\section{Author contribution}

San-hua FANG, Ka-na LIN, and Xue-qin HUANG performed the experiments; Yun-bi LU and Wei-ping ZHANG supervised all aspects of the research and revised the manuscript; and San-hua FANG and Er-qing WEI prepared the manuscript.

\section{References}

1 Singh RK, Gupta S, Dastidar S, Ray A. Cysteinyl leukotrienes and their receptors: molecular and functional characteristics. Pharmacology 2010; 85: 336-49.

2 Capra V, Thompson MD, Sala A, Cole DE, Folco G, Rovati GE. Cysteinyl- 
leukotrienes and their receptors in asthma and other inflammatory diseases: critical update and emerging trends. Med Res Rev 2007; 27: 469-527.

3 Nielsen CK, Campbell Jl, Ond JF, Morgelin M, Riesbeck K, Landberg G, et al. A novel localization of the G-protein-coupled $\mathrm{Cys}_{\mathrm{L}} \mathrm{T}_{1}$ receptor in the nucleus of colorectal adenocarcinoma cells. Cancer Res 2005; 65: 732-42.

4 Parhamifar L, Sime W, Yudina Y, Vilhardt F, Morgelin M, Sjolander A. Ligand-induced tyrosine phosphorylation of cysteinyl leukotriene receptor 1 triggers internalization and signaling in intestinal epithelial cells. PLoS One 2010; 5: e14439.

5 Fang SH, Wei EQ, Zhou Y, Wang ML, Zhang WP, Yu GL, et al. Increased expression of cysteinyl leukotriene receptor-1 in the brain mediates neuronal damage and astrogliosis after focal cerebral ischemia in rats. Neuroscience 2006; 140: 969-79.

6 Yu GL, Wei EQ, Wang ML, Zhang WP, Zhang SH, Weng JQ, et al. Pranlukast, a cysteinyl leukotriene receptor-1 antagonist, protects against chronic ischemic brain injury and inhibits the glial scar formation in mice. Brain Res 2005; 1053: 116-25.

7 Wang ML, Huang XJ, Fang SH, Yuan YM, Zhang WP, Lu YB, et al. Leukotriene D4 induces brain edema and enhances CysLT $T_{2}$ receptormediated aquaporin 4 expression. Biochem Biophys Res Commun 2006; 350: 399-404.

8 Zhang LH, Wei EQ. Neuroprotective effect of ONO-1078, a leukotriene receptor antagonist, on transient global cerebral ischemia in rats. Acta Pharmacol Sin 2003; 24: 1241-7.

$9 \mathrm{Xu} \mathrm{J}$, He L, Ahmed SH, Chen SW, Goldberg MP, Beckman JS, et al. Oxygen-glucose deprivation induces inducible nitric oxide synthase and nitrotyrosine expression in cerebral endothelial cells. Stroke 2000; 31: 1744-51.

$10 \mathrm{Kim} \mathrm{JH}, \mathrm{Yu}$ YS, Kim KW, Min BH. The role of clusterin in in vitro ischemia of human retinal endothelial cells. Curr Eye Res 2007; 32 : 693-8.

11 Fang SH, Yuan YM, Peng F, Li CT, Zhang LH, Lu YB, et al. Pranlukast attenuates ischemia-like injury in endothelial cells via inhibiting reactive oxygen species production and nuclear factor-kappaB activation. J Cardiovasc Pharmacol 2009; 53: 77-85.

12 Edgell CJ, McDonald CC, Graham JB. Permanent cell line expressing human factor VIII-related antigen established by hybridization. Proc Natl Acad Sci U S A 1983; 80: 3734-7.

13 Ahn K, Pan S, Beningo K, Hupe D. A permanent human cell line (EA. hy926) preserves the characteristics of endothelin converting enzyme from primary human umbilical vein endothelial cells. Life Sci 1995; 56: 2331-41.

14 Bouis D, Hospers GA, Meijer C, Molema G, Mulder NH. Endothelium in vitro: a review of human vascular endothelial cell lines for blood vessel-related research. Angiogenesis 2001; 4: 91-102.

15 Ge QF, Wei EQ, Zhang WP, Hu X, Huang XJ, Zhang L, et al. Activation of 5-lipoxygenase after oxygen-glucose deprivation is partly mediated via NMDA receptor in rat cortical neurons. J Neurochem 2006; 97 : 992-1004.

16 Ahmad F, Li PM, Meyerovitch J, Goldstein BJ. Osmotic loading of neutralizing antibodies demonstrates a role for protein-tyrosine phos- phatase $1 \mathrm{~B}$ in negative regulation of the insulin action pathway. J Biol Chem 1995; 270: 20503-8.

17 Lu D, Yang H, Shaw G, Raizada MK. Angiotensin Il-induced nuclear targeting of the angiotensin type 1 (AT1) receptor in brain neurons. Endocrinology 1998; 139: 365-75.

18 Sjostrom M, Jakobsson PJ, Heimburger M, Palmblad J, Haeggstrom JZ. Human umbilical vein endothelial cells generate leukotriene C4 via microsomal glutathione S-transferase type 2 and express the CysLT receptor. Eur J Biochem 2001; 268: 2578-86.

19 Jiang Y, Borrelli LA, Kanaoka Y, Bacskai BJ, Boyce JA. CysLT 2 receptors interact with $C_{y s} L_{1}$ receptors and down-modulate cysteinyl leukotriene dependent mitogenic responses of mast cells. Blood 2007; 110: 3263-70.

20 Gobeil F Jr, Bernier SG, Vazquez-Tello A, Brault S, Beauchamp MH, Quiniou C, et al. Modulation of pro-inflammatory gene expression by nuclear lysophosphatidic acid receptor type-1. J Biol Chem 2003; 278: 38875-83.

21 O'Malley KL, Jong YJ, Gonchar Y, Burkhalter A, Romano C. Activation of metabotropic glutamate receptor mGlu5 on nuclear membranes mediates intranuclear $\mathrm{Ca}^{2+}$ changes in heterologous cell types and neurons. J Biol Chem 2003; 278: 28210-9.

22 Lee DK, Lanca AJ, Cheng R, Nguyen T, Ji XD, Gobeil F Jr, et al. Agonistindependent nuclear localization of the Apelin, angiotensin AT1, and bradykinin B2 receptors. J Biol Chem 2004; 279: 7901-8.

23 Marrache AM, Gobeil F Jr, Bernier SG, Stankova J, Rola-Pleszczynski $\mathrm{M}$, Choufani S, et al. Proinflammatory gene induction by plateletactivating factor mediated via its cognate nuclear receptor. J Immunol 2002; 169: 6474-81.

24 Chen R, Mukhin YV, Garnovskaya MN, Thielen TE, lijima Y, Huang C, et al. A functional angiotensin II receptor-GFP fusion protein: evidence for agonist-dependent nuclear translocation. Am J Physiol Renal Physiol 2000; 279: F440-8.

25 Gobeil F Jr, Dumont I, Marrache AM, Vazquez-Tello A, Bernier SG, Abran D, et al. Regulation of eNOS expression in brain endothelial cells by perinuclear EP(3) receptors. Circ Res 2002; 90: 682-9.

26 Boivin B, Chevalier D, Villeneuve LR, Rousseau E, Allen BG. Functional endothelin receptors are present on nuclei in cardiac ventricular myocytes. J Biol Chem 2003; 278: 29153-63.

27 Boivin B, Lavoie C, Vaniotis G, Baragli A, Villeneuve LR, Ethier N, et al. Functional beta-adrenergic receptor signalling on nuclear membranes in adult rat and mouse ventricular cardiomyocytes. Cardiovasc Res 2006; 71: 69-78.

28 Vaniotis G, Del Duca D, Trieu P, Rohlicek CV, Hebert TE, Allen BG. Nuclear beta-adrenergic receptors modulate gene expression in adult rat heart. Cell Signal 2010; 23: 89-98.

29 Estrada R, Wang L, Jala VR, Lee JF, Lin CY, Gray RD, et al. Ligandinduced nuclear translocation of $\mathrm{S} 1 \mathrm{P}(1)$ receptors mediates Cyr61 and CTGF transcription in endothelial cells. Histochem Cell Biol 2009; 131: $239-49$

30 Li CT, Zhang WP, Lu YB, Fang SH, Yuan YM, Qi LL, et al. Oxygenglucose deprivation activates 5 -lipoxygenase mediated by oxidative stress through the p38 mitogen-activated protein kinase pathway in PC12 cells. J Neurosci Res 2009; 87: 991-1001. 